\title{
Produção de matéria seca da braquiária de acordo com os atributos químicos de um Latossolo em Selvíria, Mato Grosso do Sul
}

\author{
Rafael Montanari $^{1 *}$, Morel de Passos e Carvalho ${ }^{2}$, Marcelo Carvalho Minhoto Teixeira Filho ${ }^{3}$, \\ Flávio Carlos Dalchiavon ${ }^{4}$
}

\section{RESUMO}

Forrageiras rústicas, como as braquiárias, são predominantes na região do Cerrado, no sistema de pecuária extensiva, que favorece a degradação do solo. Entretanto, com o tempo, nem mesmo essas forrageiras conseguem bom desenvolvimento nessas áreas. O objetivo deste trabalho foi analisar a variabilidade dos atributos estudados da planta e do solo; definir as correlações lineares e espaciais entre a produtividade do capim-braquiária com os atributos químicos do solo pesquisado, e pesquisar, dentre os atributos químicos do solo, aquele que melhor se apresente para explicar a variabilidade da produtividade dessa forrageira. A pesquisa foi desenvolvida em uma área manejada com pastagem há 30 anos, na Fazenda de Ensino, Pesquisa e Extensão (FEPE) da Faculdade de Engenharia de Ilha Solteira - UNESP, em Selvíria - MS. Foi instalada a malha geoestatística num Latossolo Vermelho aluminoférrico, para a coleta de dados do solo e da planta, contendo 121 pontos amostrais, constituídos de 11 transeções, com $160 \mathrm{~m}$ de largura, na direção dos eixos cartesianos. A produção de massa de matéria seca de capim-braquiária foi baixa, apresentando alta variação. Os atributos MSr, N, PB, MO1, MO2, pHa1, pHa2, pHk1 e pHk2 não variaram aleatoriamente e apresentaram variabilidade dos dados entre baixa e alta, e seguiram padrões espaciais bem definidos, com alcances entre 17,7 e 162,9 m. Houve correlação linear significativa a 1\% entre a MSr e o N, e entre MSr e a PB. A existência dos semivariogramas cruzados $\mathrm{MSr}=\mathrm{f}(\mathrm{N})$ e $\mathrm{MSr}=\mathrm{f}(\mathrm{PB})$ atestou que essa matéria seca pode ser estimada a partir dos dados do teor de nitrogênio foliar e proteína bruta dessa forrageira.

Palavras-chave: fertilidade do solo, teor de $\mathrm{N}$ foliar, proteína bruta, agricultura de precisão, krigagem, Brachiaria decumbens.

\section{ABSTRACT \\ Dry matter production of braquiaria due to the chemical properties of an oxisol in Selvíria, Mato Grosso do Sul, Brazil}

Rustic forages as the signal-grass are predominant in areas of Cerrado in extensive livestock systems that favor soil degradation. However, with time, not even these forages can have a good development in those areas. The objective of this study was to analyze the variability of plant and soil attributes; to define the linear and spatial correlations between signal-grass yield and the chemical attributes of the studied soil, and to evaluate, among the chemical attributes of the soil, which one that best explain the variability in this forage yield. The experiment was conducted in an area that had been under pasture for more than 30 years, belonging to UNESP - Ilha Solteira Campus, located in Selvíria - MS. A geostatistical grid was installed in an oxisol, for soil and plant data collection, with 121 sampling stations, consisted of eleven transections with $160 \mathrm{~m}$ width in the direction of the Cartesian axes. The dry mass yield

\footnotetext{
Recebido para publicação em 28/12/2011 e aprovado em 03/05/2013.

'Engenheiro-Agrônomo. Doutor. Faculdade de Engenharia, Universidade Estadual Paulista "Júlio de Mesquita Filho", Campus de Ilha Solteira, Avenida Brasil, 56, Centro, Caixa Postal 31, 15385-000, Ilha Solteira, São Paulo, Brasil. montanari@agr.feis.unesp.br (autor para correspondência)

2Engenheiro-Agrônomo. Doutor. Faculdade de Engenharia, Universidade Estadual Paulista "Júlio de Mesquita Filho", Campus de Ilha Solteira, Avenida Brasil, 56, Centro, Caixa Postal 31, 15385-000, Ilha Solteira, São Paulo, Brasil. morel@agr.feis.unesp.br

${ }^{3}$ Engenheiro-Agrônomo. Doutor. Faculdade de Engenharia, Universidade Estadual Paulista "Júlio de Mesquita Filho", Campus de Ilha Solteira, Avenida Brasil, 56, Centro, Caixa Postal 31, 15385-000, Ilha Solteira, São Paulo, Brasil. mcmtf@yahoo.com.br

${ }^{4}$ Professor efetivo do Instituto Federal de Mato Grosso, Campus Campo Novo do Parecis, Departamento de Agronomia, Rodovia MT 235, km 12, zona rural, caixa postal n. 100, cep: 78 360-000, Campo Novo do Parecis-MT, email: flavio.dalchiavon@cnp.ifmt.edu.br
} 
of signal-grass was low, presenting high variation. The attributes MSr, N, PB, MO1, MO2, pHa1, pHa2, pHk1 and pHk2 did not vary at random. They presented data variability from low to high and followed clearly defined spatial patterns, ranging between 17.7-162.9 $\mathrm{m}$. There was significant linear correlation at $1 \%$ between $\mathrm{MSr}$ and $\mathrm{N}$ leaf, and between $\mathrm{MSr}$ and $\mathrm{PB}$. The cross semivariograms $\mathrm{MSr}=\mathrm{f}(\mathrm{N})$ and $\mathrm{MSr}=\mathrm{f}(\mathrm{PB})$ confirmed that the dry matter can be estimated from data of nitrogen leaf and crude protein content of this forage.

Key words: soil fertility, nitrogen content, crude protein, precision farming, kriging, Brachiaria decumbens.

\section{INTRODUÇÃO}

O Brasil possui 220 milhões de hectares de pastagens, sendo a gramínea predominante a do gênero Brachiaria, com $55 \%$ de $B$. decumbens, que apresenta boa adaptação, principalmente às áreas de Cerrado, bioma no qual a qualidade química do soloé mais deficiente (Montanari et al., 2013). Contudo, com o tempo, nem mesmo essas forrageiras rústicas têm conseguido bom desenvolvimento nesses solos, pois o consumo da massa verde pelo animal, a falta de reposição dos nutrientes, a acidificação do solo, a perda da matéria orgânica e a compactação do solo diminuem a eficiência das pastagens (Moreira et al., 2005; Pariz et al., 2011).

A importância das pastagens na produção de bovinos no Brasil está atribuída, entre outros fatores, ao seu baixo custo de produção (Santos et al., 2009). No entanto, a recuperação de áreas degradadas, por meio de técnicas adequadas de manejo, cuja implementação depende do melhor entendimento dos mecanismos envolvidos e dos limites a serem respeitados no seu uso sustentável, é um dos caminhos para se promover o aumento da produção de carne (Pariz et al., 2011).

Assim, a boa qualidade do solo é um fator determinante da produtividade elevada de matéria seca da forragem. $\mathrm{O}$ nitrogênio é um dos principais nutrientes a ser aplicado, por seu destaque como fator de produção dessa massa de matéria seca, pois proporciona maior perfilhamento e produtividade, melhorando a qualidade da forragem produzida e aumentando a capacidade de animais por área (Mendonça et al., 2013). Sabe-se que a fertilidade adequada do solo é um fator importante na longevidade das pastagens e pode afetar a degradação, pois, normalmente, a degradação da pastagem apresenta-se mais frequentemente em solos com baixa fertilidade.

Além disso, a taxa de mineralização da matéria orgânica reduz o estoque de nitrogênio, com o maior tempo de uso da pastagem, implicando o agravamento da degradação, especialmente com o aumento da taxa de lotação. No Brasil, especificamente em pastagens, praticamente não são utilizados fertilizantes e, ainda, em áreas localizadas que promovem renovação da pastagem com fertilização, os fertilizantes são utilizados apenas na implantação e essas áreas têm, em médio prazo, sofrido, novamente, processos de degradação (Fernandes et al., 2008).

Em geoestatística, a variabilidade espacial pode ser representada por mapas, confeccionados a partir de estimativas da variável estudada, sendo essa técnica definida como interpolação por krigagem. Pode-se, também, efetuar a interpolação por co-krigagem, a partir de estimativas de duas variáveis que se correlacionam (primária e secundária). Os dois processos podem ser descritos como métodos que minimizam a variância estimada por meio de análise de regressão, levando-se em conta a dependência entre os dados distribuídos no espaço (Trangmar et al., 1985; Bottega et al., 2011).

$\mathrm{Na}$ tentativa de se estabelecer um indicador da qualidade química do solo, que venha a elucidar as possíveis causas de degradação das pastagens de Brachiaria decumbens, para o local estudado, a partir dos atributos da planta e do solo, este trabalho objetivou: a) analisar a variabilidade desses atributos e b) definir as correlações lineares e espaciais entre os atributos da planta e do solo.

\section{MATERIAL E MÉTODOS}

$\mathrm{O}$ experimento foi realizado na área experimental da Fazenda de Ensino e Pesquisa - Faculdade de Engenharia de Ilha Solteira (FEPE/UNESP), localizada no município de Selvíria (MS), em latitude de $20^{\circ} 22^{\prime} 31^{\prime \prime S}$ e longitude de $51^{\circ} 25^{\prime} 5^{\prime \prime} \mathrm{O}$. A precipitação média anual é de $1300 \mathrm{~mm}$, a temperatura média é de $23,7^{\circ} \mathrm{C}$. O tipo climático é Aw, segundo Koeppen. O solo no qual a malha experimental foi instalada é um Latossolo Vermelho aluminoférrico (Embrapa, 2006).

A área na qual foi estabelecida a pesquisa vem sendo manejada com pastagem há 30 anos, para criação de gado, e estava vedada à circulação de animais por 21 dias. A capacidade de suporte da área está entre 1,0 e 1,5 UA. A planta-teste pesquisada foi o capim-braquiária (Brachiaria decumbens), com uma altura de 0,20 a 0,30 m. Essa pastagem não recebeu nenhum tipo de adubação e de tratamento fitossanitário. 
Foram definidas as direções $\boldsymbol{x}$ e $\boldsymbol{y}$ do sistema de coordenadas cartesianas, num lançante da pastagem de braquiária, e efetuou-se o estaqueamento da malha experimental. Um grid geoestatístico regular foi alocado, constituído de 11 transeções com 160 m de largura na direção dos eixos cartesianos. As transeções foram espaçadas de $20 \mathrm{~m}$, com pontos de amostragem na forma de $20 \mathrm{~m}$ x $20 \mathrm{~m}$, contendo 81 deles. Também, foram alocados dentro da grande malha mais 40 pontos, com espaçamentos menores que os mencionados, com o objetivo de refinamento da distância entre os pontos, para se apurar a obtenção do alcance da dependência espacial, com espaçamentos de 7,5; 5,0 e de 7,5 m entre eles. Portanto, no total foram amostrados 121 pontos, em uma área global de estudo de $25.600 \mathrm{~m}^{2}$ (Figura 1).

Todos os atributos do solo e da planta foram avaliados em amostras coletadas, individualmente, no entorno de cada ponto amostral da malha experimental. Os atributos do solo foram: a) teor de matéria orgânica (MO), b) pH em água (pHa), c) pH em cloreto de potássio (pHk), d) delta $\mathrm{pH}(\boldsymbol{\Delta} \mathbf{p H})$, e e) acidez potencial $(\mathbf{H}+\mathbf{A l})$, coletados em maio de 2008 em duas profundidades, a saber: a) 0,000,10 m, e b) 0,10-0,20 m, e analisados conforme Raij et al. (2001). Os atributos da planta foram: a) massa de matéria seca da forragem (MSF), b) massa de matéria seca relativa da forragem (MSr), c) teor de clorofila foliar (CLO), d) teor de nitrogênio foliar (N), e e) teor de proteína bruta (PB), coletados ou obtidos acima da altura de pastejo.
Para coleta da amostra destinada à avaliação da massa verde de capim-braquiária, utilizou-se um gabarito com dimensões de 2 x $2 \mathrm{~m}$, e o material existente dentro do quadrado foi ceifado a aproximadamente 0,20 a $0,25 \mathrm{~m}$ do solo. Em seguida, retirou-se desse material uma amostra, que foi acondicionada em saco de papel, pesada e colocada em estufa de circulação de ar forçada, determinando-se, assim, a massa de matéria seca da forragem. A massa de matéria seca relativa foi obtida por meio da relação entre as massas verde e seca da forragem. Para determinação indireta do teor de clorofila do capimbraquiária, utilizou-se um clorofilômetro digital (SPAD) e foram realizadas três leituras por ponto, na segunda folha desenvolvida. O teor de nitrogênio foliar foi analisado na parte da planta que simula o que o animal pasteja (brotação nova e folhas verdes), segundo metodologia descrita por Werner et al. (1997). O teor de proteína bruta foi determinado conforme a metodologia descrita em Silva \& Queiroz (2002).

Para cada atributo estudado, efetuou-se a análise descritiva clássica, com auxílio do software estatístico SAS (Schlotzhaver \& Littell, 1997). Posteriormente, realizou-se a identificação dos outliers; após identificados, foram calculados, efetuando-se a substituição dos seus valores pelo valor médio dos circunvizinhos contidos na malha. Para testar a hipótese de normalidade, ou de lognormalidade, realizou-se o teste de Shapiro \& Wilk a $1 \%$. Também, foi montada a matriz de correlação, objetivando efe-

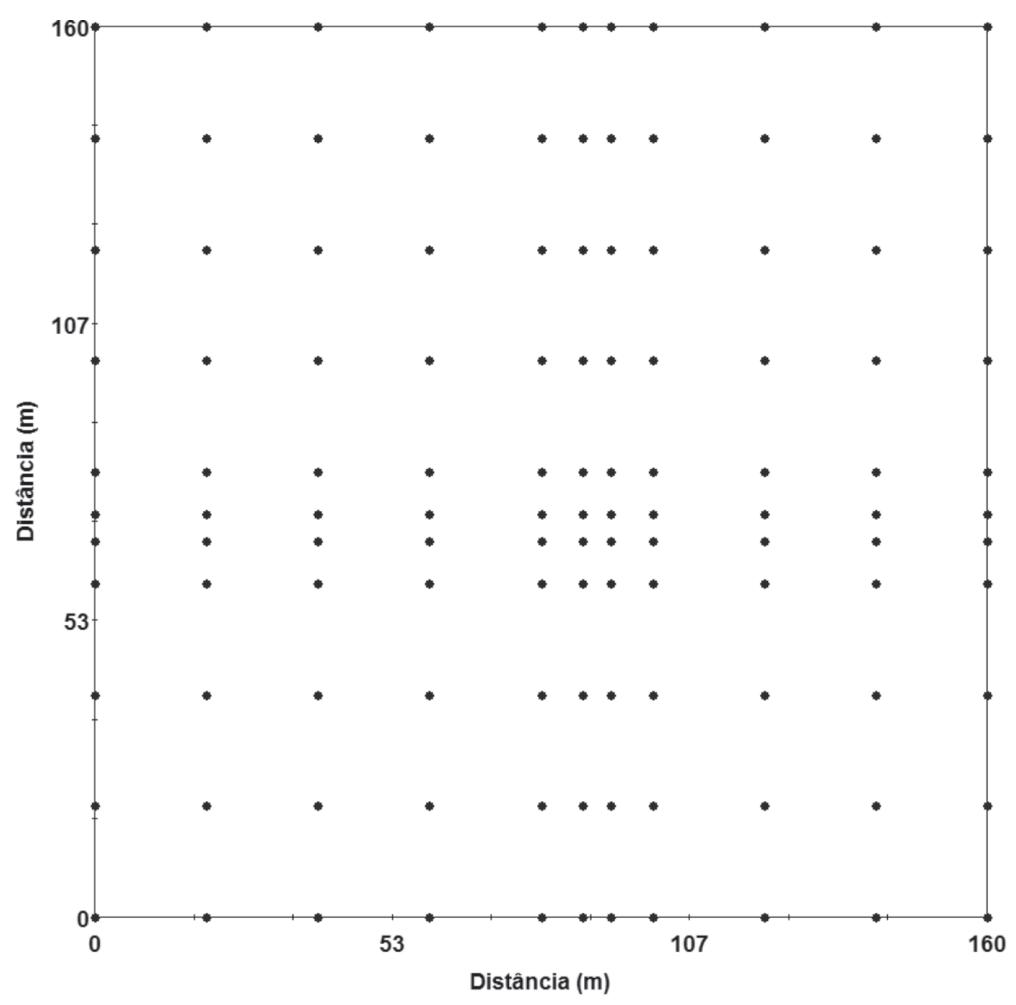

Figura 1. Esquema da malha geoestatística de amostragem. 
tuar as correlações lineares simples para as combinações, duas a duas, entre todos os atributos estudados.

Isoladamente, para cada atributo, foi analisada sua dependência espacial, pelo cálculo do semivariograma simples. Contudo, para aqueles que apresentaram interdependência espacial, calcularam-se também seus semivariogramas cruzados, com base nos pressupostos de estacionaridade da hipótese intrínseca, pelo uso do pacote Gamma Design Software (GS $\left.{ }^{+}, 2004\right)$. Para cada atributo, foram relacionados o efeito pepita (Co), o alcance (Ao) e o patamar (Co + C) $(\mathrm{GS}+, 2004)$.

Trabalhando-se na obtenção do número ideal de vizinhos, foram obtidos, por meio da interpolação, os mapas de krigagem e de cokrigagem, para análise da dependência e da interdependência espacial entre os atributos.

\section{RESULTADOS E DISCUSSÃO}

Os resultados referentes à análise descritiva para os atributos MSr, CLO, N, PB, pHa1, H+Al1, H+Al2, $\Delta$ pH1 e $\Delta \mathrm{pH} 2$, apresentados na Tabela 1 , indicaram ajuste a distribuição normal, já os atributos MSF, MO1 e pHa2 apresentaram distribuição de frequência do tipo tendendo a normal; a MO2, ajustou-se à distribuição log-normal e os pHk1 e pHk2 apresentaram-se indeterminado. Resultados semelhantes para o atributo $\mathrm{pHa}$ também foi verificado por Cavalcante et al. (2007). Já, para o teor de matéria orgânica, resultados similares foram encontrados por Pariz et al. (2011) que encontraram, para um Latossolo sob pastagem de Brachiaria, distribuição de frequência do tipo tendendo a normal. Os valores da média e mediana estão próximos, mostrando distribuições simétricas para todos os atributos, o que pode ser confirmado pelos valores de assimetria próximos de zero. Mais importante que a normalidade dos dados é a ocorrência, ou não, do chamado efeito proporcional, em que a média e a variabilidade dos dados sejam constantes na área de estudo, fato observado neste trabalho, ou seja, ocorre a estacionaridade necessária ao uso da geoestatística (Tabela 1).

A variabilidade de um atributo pode ser classificada, segundo Warrick \& Nielsen (1980) (estes autores dão a classificação de baixa, média e alta para os CV’s), de acordo com a magnitude do seu coeficiente de variação. Verifica-se, na Tabela 1, que os coeficientes de variação (CV’s) situaram-se entre baixos e altos, com destaque para o pHa1, pHa2, pHk1 e pHk2, que apresentaram menores valores. $\mathrm{O}$ valor médio do teor de $\mathrm{N}$ foliar apresenta-se abaixo da faixa adequada (12 a $20 \mathrm{~g} \mathrm{~kg}^{-1}$ de $\mathrm{N}$ por massa de matéria seca), descrita por Werner et al. (1997), refletindo assim que o capim-braquiária está deficiente em N. Manarin (2000), trabalhando com nitrogênio no capim Mombaça, obteve valores entre 41 e 45 unidade de valor SPAD nas folhas recém-expandidas. Entretanto, o número de infor- mações sobre o teor de clorofila de gramíneas forrageiras tropicais é muito pequeno.

O teor médio de proteína bruta do capim-braquiária foi de 6,6\% (Tabela 1). O baixo nível de proteína observado nas gramíneas tropicais deve-se ao metabolismo fotossintético $\mathrm{C}_{4}$, assim como à anatomia foliar e à alta proporção de caule, em relação à das folhas. Segundo Milford \& Minson (1966), valores inferiores a 7\% de PB na forragem provocam redução no consumo da matéria seca delas pelos animais, por causa da significativa redução da digestibilidade da MS, por deficiência de N para as bactérias. Queiroz Filho et al. (1986), estudando a aplicação de $\mathrm{N}\left(0 ; 50\right.$ e $\left.100 \mathrm{~kg} \mathrm{ha}^{-1}\right)$, em diferentes intervalos de cortes da Brachiaria humidicula, observaram incremento no teor de proteína, especialmente em intervalos de corte de 40 dias após a rebrota.

A massa média de matéria seca de capim-braquiária (2184 $\mathrm{kg} \mathrm{ha}^{-1}$ ) foi relativamente baixa (Tabela 1), quando comparada com a produtividade média $\left(7730 \mathrm{~kg} \mathrm{ha}^{-1} \mathrm{de}\right.$ MS), no período do verão, indicada por Pedreira \& Mattos (1981). Já Serrão \& Simão Neto (1971) citam que, em solos de baixa fertilidade, a produtividade média anual da $B$. decumbens reduz-se bastante, podendo atingir até 1000 $2000 \mathrm{~kg} \mathrm{ha}^{-1} \mathrm{de}$ MS. Montanari et al. (2013) encontraram uma média de produtividade de $2964 \mathrm{~kg} \mathrm{ha}^{-1} \mathrm{em}$ pastagem no Cerrado. Portanto, a produtividade de massa de matéria seca de capim-braquiária constatada foi baixa, por causa da baixa fertilidade do solo, sendo que essa gramínea estava deficiente em nitrogênio. De acordo com Werner (1986), o nitrogênio é de importância fundamental para o crescimento de gramíneas, tendo influência no tamanho das folhas e do colmo e no desenvolvimento de perfilhos.

Os teores médios de matéria orgânica foram de 33,8 e 25,0 $\mathrm{g} \mathrm{dm}^{-3}$, nas camadas do solo de 0,00-0,10 e 0,10-0,20 $\mathrm{m}$, respectivamente (Tabela 1). O maior teor de MO nesta camada do solo foi devido à deposição e acúmulo dos excrementos bovinos e resíduos vegetais sobre a superfície do solo.

Os valores médios de $\mathrm{pHa}$ e $\mathrm{pHk}$ foram maiores na camada de 0,10-0,20 m, evidenciando que o solo estava com menor acidez nesta camada, em relação à camada mais superficial (Tabela 1). Entretanto, constatou-se que a acidez potencial foi superior na camada de 0,00-0,10 m. Isto provavelmente ocorreu, porque esta camada do solo apresentava maior teor de $\mathrm{Al}$ trocável. Os valores médios de $\Delta \mathrm{pH}$ nas camadas de $0,00-0,10$ e $0,10-0,20 \mathrm{~m}$ foram iguais a $-1,29$, demonstrando assim que este solo é eletronegativo.

Por meio da matriz de correlação (Tabela 2) realizada, foram constatadas correlações significativas positivas entre os atributos da planta, CLO, N e PB, e os do solo, pHa2, pHk1 e pHk2, com coeficientes de correlação variando entre $0,184^{*}$ e $0,295^{* *}$, e correlações negativas entre o N e PB x H+Al2, com coeficiente de $-0,301^{* *}$. Já para os 
Tabela 1. Análise descritiva inicial de alguns atributos da produtividade da braquiária e de um Latossolo Vermelho aluminoférrico de Selvíria (MS)

\begin{tabular}{|c|c|c|c|c|c|c|c|c|c|c|}
\hline \multirow{3}{*}{ Atributo $^{(a)}$} & \multicolumn{10}{|c|}{ Medidas estatísticas descritivas } \\
\hline & \multirow{2}{*}{ Média } & \multirow{2}{*}{ Mediana } & \multicolumn{2}{|c|}{ Valor } & \multirow{2}{*}{$\begin{array}{l}\text { Desvio } \\
\text { padrão }\end{array}$} & \multicolumn{3}{|c|}{ Coeficiente } & \multicolumn{2}{|c|}{ Probabilidade do teste $^{(\mathrm{b})}$} \\
\hline & & & Mínimo & Máximo & & Variação (\%) & Curtose & Assimetria & $\operatorname{Pr}<w$ & DF \\
\hline \multicolumn{11}{|c|}{ Atributos da Planta } \\
\hline $\operatorname{MSF}\left(\mathrm{kg} \mathrm{ha}^{-1}\right)$ & 2184 & 2040 & 758 & 3800 & 671 & 30,5 & $-0,530$ & 0,394 & 0,015 & $\mathrm{TN}$ \\
\hline $\operatorname{MSr}(\%)$ & 33,6 & 34,0 & 21,7 & 42,4 & 3,01 & 8,9 & 1,466 & $-0,276$ & 0,071 & NO \\
\hline CLO (SPAD) & 29,99 & 29,60 & 17,00 & 42,50 & 4,435 & 14,8 & 0,438 & 0,284 & 0,212 & NO \\
\hline $\mathrm{N}\left(\mathrm{g} \mathrm{kg}^{-1}\right)$ & 10,49 & 10,15 & 6,16 & 15,33 & 2,00 & 19,1 & $-0,669$ & 0,244 & 0,058 & NO \\
\hline $\mathrm{PB}(\%)$ & 6,6 & 6,3 & 3,9 & 9,6 & 1,249 & 19,1 & $-0,669$ & 0,244 & 0,058 & NO \\
\hline \multicolumn{11}{|c|}{ Atributos Químicos do Solo } \\
\hline $\mathrm{MO} 1\left(\mathrm{~g} \mathrm{dm}^{-3}\right)$ & 33,8 & 33,3 & 22,3 & 51,1 & 6,8 & 20,1 & $-0,393$ & 0,429 & 0,014 & $\mathrm{TN}$ \\
\hline $\mathrm{MO} 2\left(\mathrm{~g} \mathrm{dm}^{-3}\right)$ & 25,0 & 24,3 & 13,5 & 42,9 & 6,1 & 24,6 & $-0,317$ & 0,057 & 0,888 & $\mathrm{LN}$ \\
\hline pHa1 & 5,90 & 5,90 & 5,35 & 6,35 & 0,18 & 3,0 & 0,542 & $-0,129$ & 0,664 & NO \\
\hline $\mathrm{pHa} 2$ & 6,03 & 6,01 & 5,32 & 6,65 & 0,23 & 3,8 & 0,205 & 0,520 & 0,039 & $\mathrm{TN}$ \\
\hline pHk1 & 4,63 & 4,58 & 4,29 & 5,22 & 0,19 & 4,2 & - & - & - & IN \\
\hline $\mathrm{pHk} 2$ & 4,73 & 4,68 & 4,39 & 5,35 & 0,21 & 4,5 & - & - & - & IN \\
\hline$\ddot{\mathrm{ApH}} 1^{(\mathrm{c})}$ & $-1,29$ & $-1,30$ & $-0,94$ & $-1,69$ & 0,12 & 9,5 & 0,946 & 0,062 & 0,135 & NO \\
\hline$\ddot{\mathrm{ÄpH}} 2^{\text {(c) }}$ & $-1,29$ & $-1,29$ & $-1,02$ & $-1,57$ & 0,11 & 8,3 & $-0,177$ & $-0,021$ & 0,979 & NO \\
\hline $\mathrm{H}+\mathrm{All}\left(\mathrm{mmolc} \mathrm{dm}^{-3}\right)$ & 26,12 & 26,55 & 14,41 & 37,99 & 4,15 & 15,9 & 0,264 & $-0,123$ & 0,703 & NO \\
\hline $\mathrm{H}+\mathrm{Al} 2\left(\mathrm{mmolc} \mathrm{dm}^{-3}\right)$ & 22,40 & 22,13 & 12,70 & 39,25 & 4,80 & 21,4 & 0,443 & 0,368 & 0,271 & NO \\
\hline
\end{tabular}


atributos da planta, houve correlação significativa positiva entre MSF, N e PB x CLO, com coeficientes de correlação variando entre $0,192^{*}$ e $0,610^{* *}$, e correlação negativa para MSF, CLO, N e PB x MSr, variando entre $-0,200^{*}$ e 0,268**. Santos (1997) também obteve alto coeficiente de correlação entre as leituras de clorofila, nas lâminas foliares de capim-braquiária, e as doses de nitrogênio aplicadas na fase de crescimento dessa gramínea. Com relação aos atributos do solo, foram verificadas correlações significativas entre MO1 e H+Al2 x MO2; pHa2, pHk1, pHk2 e $\Delta \mathrm{pH} 1 \times \mathrm{pHa} 1 ; \mathrm{pHk} 1, \mathrm{pHk} 2, \Delta \mathrm{pH} 2, \mathrm{H}+\mathrm{Al} 1 \mathrm{e} \mathrm{H}+\mathrm{Al} 2 \times \mathrm{pHa} 2 ;$ $\mathrm{pHk} 2, \Delta \mathrm{pH} 1, \mathrm{H}+\mathrm{Al} 1 \mathrm{eH}+\mathrm{Al} 2 \times \mathrm{pHk} 1 ; \Delta \mathrm{pH} 2, \mathrm{H}+\mathrm{All} \mathrm{eH}+\mathrm{Al} 2$ x pHk2; e $\Delta \mathrm{pH} 1, \Delta \mathrm{pH} 2 \mathrm{e} H+\mathrm{Al} 2 \times \mathrm{H}+\mathrm{A} 11$. Esses resultados confirmam a estreita correlação entre os atributos relacionados com a acidez do solo (Tabela 2).

No estudo das correlações lineares entre a MSr e os atributos do solo e da planta, houve correlação significativa (a 1\%), e negativa, entre MSr e os teores de nitrogênio e de clorofila, ou seja, o aumento do $\mathrm{N}$ foliar e o da clorofila proporcionaram redução na $\mathrm{MSr}$ da braquiária. Esta redução provavelmente ocorreu porque o cálculo da MSr leva em consideração, além da massa seca, a quantidade de massa verde fresca, que é maior nas folhas com menos fibra e representam a melhor qualidade da forragem, (1991), avaliando as respostas de gramíneas forrageiras à adubação nitrogenada, que, geralmente, apresenta correlação positiva com o CLO, constataram incrementos marcantes na produção de massa de matéria seca da Brachiaria spp., quando esta foi submetida a doses cres-

A análise geoestatística (Tabela 3) evidenciou que houve dependência espacial para os semivariogramas dos atributos \#MSF, \#pHa1 e pHk2, que se ajustaram ao modelo esférico, para os atributos $\mathrm{MSr}, \mathrm{N}, \mathrm{MO} 1, \mathrm{MO} 2, \mathrm{pHa} 2$ e pHk1, que se ajustaram ao modelo exponencial, e para o semivariograma da \#PB, que se ajustou ao modelo gaussiano. Os modelos esféricos e exponenciais apresentam-se como teóricos mais comuns aos atributos do solo e da planta (Trangmar et al., 1985; Montanari et al., 2010). Segundo Grego \& Vieira (2005), o modelo matemático esférico é o que predomina nos trabalhos em ciência do solo. Cavalcante et al. (2007) e Montanari (2009), avaliando um Latossolo Vermelho, encontraram os mesmos modelos de semivariogramas (esférico e exponencial), quando estudaram o $\mathrm{pH}$ em $\mathrm{CaCl} 2$.

Os atributos obtiveram alcances que variaram de 17,7 m (MO1) a 164,3 m (\#MSF). Assim, estes atributos do solo e da planta mostraram que a distribuição deles no pendência espacial variaram de 50,0\% (moderada para a \#MSF) a 99,9\% (alta para a pHk1). Com relação, aos $\Delta \mathrm{pH} 1$ e $\Delta \mathrm{pH}, \mathrm{H}+\mathrm{Al} 1$ e H+Al2, e CLO, não foi encontrada variapor causa dos teores altos de $\mathrm{N}$ e clorofila. Carvalho et al. centes de N. espaço não é aleatória, uma vez que suas classes de de-

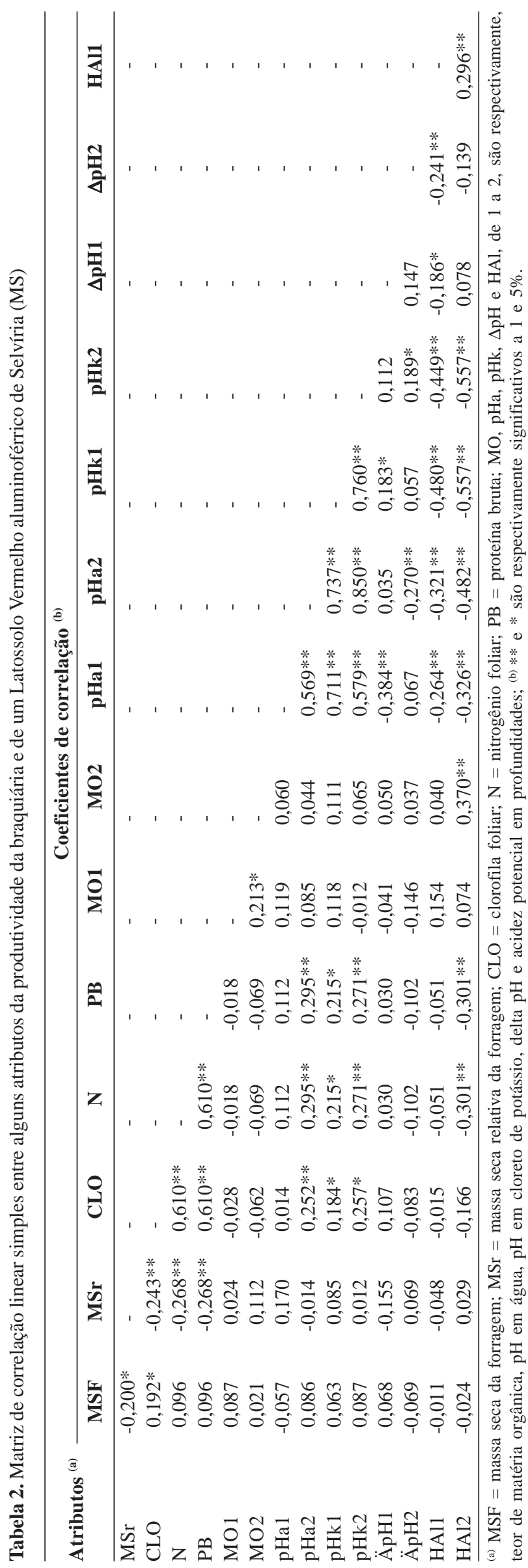

Rev. Ceres, Viçosa, v. 60, n.4, p. 519-527, jul/ago, 2013 
bilidade espacial, verificando-se efeito pepita puro. O conhecimento dos valores de alcance e as localizações das áreas, onde estão concentrados os maiores e, ou, menores valores de determinada variável química, são importantes para o planejamento do manejo da fertilidade do solo, na agricultura de precisão. Souza et al. (1998), estudando a variabilidade espacial de atributos químicos, em relação a sistemas de manejo, observaram que o sistema pastagem teve maiores alcances desses atributos, em relação ao sistema plantio direto (Tabela 3).

Tabela 3. Parâmetros dos semivariogramas simples e cruzados ajustados para alguns atributos da produtividade da braquiária e de um Latossolo Vermelho aluminoférrico de Selvíria (MS)

\begin{tabular}{|c|c|c|c|c|c|c|c|c|}
\hline \multirow{3}{*}{ Atributo $^{(a)}$} & \multicolumn{8}{|c|}{ Parâmetros } \\
\hline & \multirow{2}{*}{ Modelo $^{(b)}$} & \multirow{2}{*}{$\begin{array}{c}\text { Efeito } \\
\text { Pepita }\left(\mathrm{C}_{0}\right)\end{array}$} & \multirow{2}{*}{$\begin{array}{c}\text { Patamar } \\
\left(\mathrm{C}_{0}+\mathrm{C}\right)\end{array}$} & \multirow{2}{*}{$\begin{array}{l}\text { Alcance } \\
\left(\mathbf{A}_{0}\right)(\mathbf{m})\end{array}$} & \multirow{2}{*}{$\mathbf{r}^{2}$} & \multirow{2}{*}{$\mathrm{SQR}^{(\mathrm{c})}$} & \multicolumn{2}{|c|}{$\begin{array}{c}\text { Avaliador da } \\
\text { dependência espacial }\end{array}$} \\
\hline & & & & & & & $\mathbf{A D E}^{(\mathrm{d})}$ & Classe \\
\hline \multicolumn{9}{|c|}{ X(h) simples dos atributos da planta e do solo } \\
\hline \#MSF $\left(\mathrm{kg} \mathrm{ha}^{-1}\right)$ & esf. (160) & $2,433.10^{5}$ & $4,867.10^{5}$ & 164,3 & 0,977 & $1,360.10^{9}$ & 50,0 & Moderada \\
\hline $\operatorname{MSr}(\%)$ & $\exp (42)$ & $2,200 \cdot 10^{-1}$ & 8,559 & 25,0 & 0,844 & 2,4 & 97,4 & Forte \\
\hline $\mathrm{N}\left(\mathrm{g} \cdot \mathrm{Kg}^{-1}\right)$ & exp. (70) & $2,3.10^{-1}$ & 3,432 & 24,3 & 0,809 & $4,34 \cdot 10^{-1}$ & 93,3 & Forte \\
\hline \#PB $(\%)$ & gau. (51) & $3,45 \cdot 10^{-1}$ & 1,029 & 25,6 & 0,954 & $1,75.10^{-2}$ & 66,5 & Moderada \\
\hline $\operatorname{MO1}\left(\mathrm{g} \mathrm{dm}^{-3}\right)$ & exp. (49) & 1,03 & $3,091.10$ & 17,7 & 0,809 & $1,96.10$ & 96,7 & Forte \\
\hline $\mathrm{MO} 2\left(\mathrm{~g} \mathrm{dm}^{-3}\right)$ & exp.(50) & 9,26 & $2,98.10$ & 52,2 & 0,315 & $1,98.10$ & 68,7 & Moderada \\
\hline \#pHa1 & esf. (63) & $1,239.10^{-2}$ & $2,488 \cdot 10^{-2}$ & 41,9 & 0,830 & $2,789.10^{-5}$ & 50,2 & Moderada \\
\hline pHa2 & exp. (68) & $1,950.10^{-2}$ & $5,870 \cdot 10^{-2}$ & 162,9 & 0,848 & $3,498.10^{-4}$ & 66,8 & Moderada \\
\hline pHk1 & exp. (54) & $1,00.10^{-5}$ & $1,820.10^{-2}$ & 41,7 & 0,773 & $3,748 \cdot 10^{-5}$ & 99,9 & Forte \\
\hline pHk2 & esf. (54) & $1,808.10^{-2}$ & $3,620 \cdot 10^{-2}$ & 119,5 & 0,944 & $1,639.10^{-5}$ & 50,1 & Moderada \\
\hline \multicolumn{9}{|c|}{ X(h) cruzado entre atributos da planta } \\
\hline $\mathrm{MSr}=\mathrm{f}(\mathrm{N})(\%)$ & gau. & $-1,000.10^{-6}$ & $-1,071$ & 15,7 & 0,259 & 1,84 & 99,9 & Forte \\
\hline $\mathrm{MSr}=\mathrm{f}(\mathrm{PB})(\%)$ & gau. & $-1,000 \cdot 10^{-2}$ & $-4,910 \cdot 10^{-1}$ & 13,0 & 0,134 & $7,810.10^{-1}$ & 99,8 & Forte \\
\hline
\end{tabular}

(a) MSF = massa de matéria seca da forragem; $\mathrm{MSr}=$ massa de matéria seca relativa da forragem; $\mathrm{N}=$ nitrogênio foliar; $\mathrm{PB}=$ proteína bruta foliar; $\mathrm{MO}, \mathrm{pHa}, \mathrm{pHk}$, de 1 a 2, são respectivamente o teor de matéria orgânica; $\mathrm{pH}$ em água; $\mathrm{pH}$ em cloreto de potássio, em profundidades, \# = semivariograma em que foi extraída a tendência; (b) exp = exponencial, esf = esférico e gau = gaussiano; modelo sucedido por número entre parênteses, significando o número de pares no primeiro lag; (c) $\mathrm{SQR}=$ soma dos quadrados dos resíduos; (d) $\mathrm{ADE}=$ avaliador da dependência espacial.

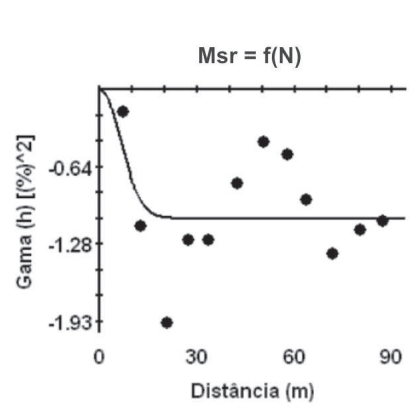

A
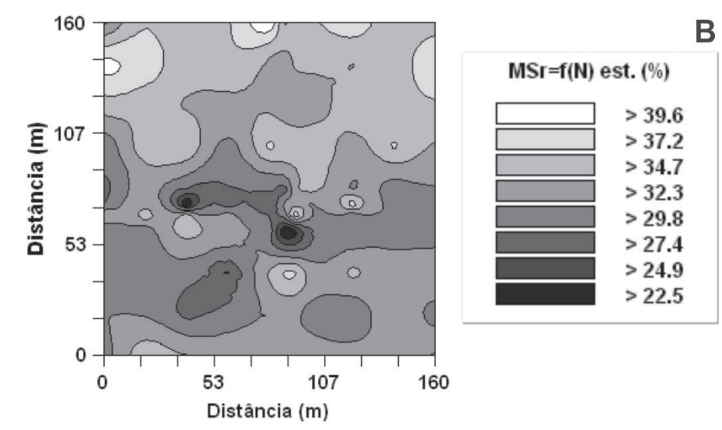

C
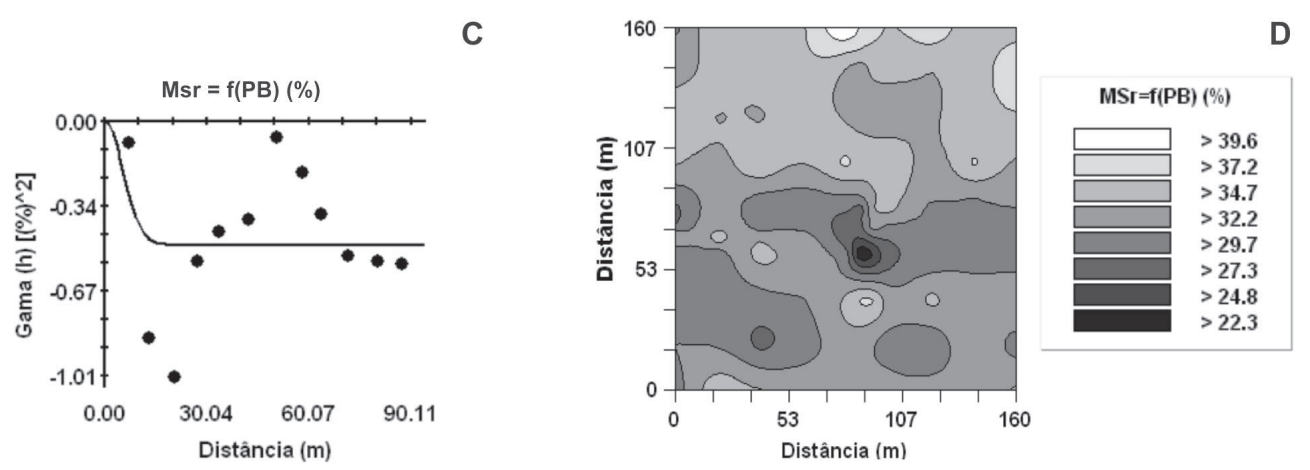

Figura 2. Semivariogramas cruzados e mapas de cokrigagem de atributos da produtividade da braquiária e de um Latossolo Vermelho aluminoférrico de Selvíria (MS). 
Quando realizado o semivariograma cruzado entre os atributos da planta, foram encontradas correlações espaciais negativas entre $\mathrm{MSr}$ e $\mathrm{N}$ e $\mathrm{MSr}$ e $\mathrm{PB}$, em que se observou uma forte dependência espacial $(\mathrm{ADE}=99,9 \mathrm{e}$ $99,8 \%$, respectivamente); o modelo ajustado para ambos foi o gaussiano (Tabela 3 e Figura 2). Montanari et al. (2010) encontraram semivariogramas cruzados para a produtividade de feijão, em função de um atributo químico do solo, que foi o potencial hidrogeniônico para as profundidades de 0,00-0,10 e 0,10-0,20 m (Figura 2).

Assim, como houve correlação linear significativa a $1 \%$ entre a MSr e o $\mathrm{N}$, houve satisfatório ajuste semivariográfico. Portanto, analisando-se a Figura 2, podese inferir que o teor de $\mathrm{N}$ foliar apresentou-se como bom indicador da qualidade nutricional da planta forrageira, quando destinada à produção de massa de matéria seca da braquiária, em solo de cerrado. Constatou-se, também, ajuste semivariográfico satisfatório entre a MSr e a PB, pois houve correlação linear significativa a $1 \%$. Portanto, observando-se a Figura 2, pode-se inferir que o teor de proteína bruta (PB) mostrou-se também bom indicador da qualidade da planta forrageira, em relação à produção de massa de matéria seca da braquiária, em solo de cerrado.

\section{CONCLUSÕES}

Os atributos MSr, N, PB, MO1, MO2, pHa1, pHa2, pHk1 e pHk2 não variaram aleatoriamente, apresentaram variabilidade dos dados entre baixa e alta, e seguiram padrões espaciais bem definidos, com alcances entre 17,7 e $162,9 \mathrm{~m}$.

O conteúdo de matéria orgânica foi tido como um bom indicador da qualidade do solo, quando correlacionado com a produtividade de capim braquiária.

Houve correlação linear significativa a $1 \%$ entre a MSr e o N e entre MSr e a PB; , também a correlação espacial da $\mathrm{MSr}=\mathrm{f}(\mathrm{N})$ e da $\mathrm{MSr}=\mathrm{f}(\mathrm{PB})$, atestando que a matéria seca pode ser estimada a partir dos dados dos teores de nitrogênio foliar e de proteína bruta e, como resultado, poder-se-ão efetuar, com eles, previsões de resultados futuros para o capim braquiária.

O teor de proteína bruta evidenciou-se como bom indicador da qualidade da planta forrageira, em relação à produção de massa de matéria seca da braquiária.

\section{REFERÊNCIAS}

Bottega EL, Silva AS, Costa MM \& Bottega SP (2011) Cokrigagem na estimativa dos teores de $\mathrm{Ca}$ e $\mathrm{Mg}$ em um Latossolo Vermelho distroférrico. Revista Ciência Agronômica, 42:821-828.

Carvalho MM, Martins CE, Verneque RS \& Siqueira C (1991) Resposta de uma espécie de braquiária à fertilização com nitrogênio e potássio em um solo ácido. Revista Brasileira de Ciência do Solo, 15:195-200.
Cavalcante GES, Alves MC, Souza ZM \& Pereira GT (2007) Variabilidade espacial de atributos químicos do solo sob diferentes usos e manejos. Revista Brasileira de Ciência do Solo, 31:1329-1339.

Empresa Brasileira de Pesquisa Agropecuária (2006) Sistema brasileiro de classificação de solos. $2^{\mathrm{a}}$ ed. Rio de Janeiro, Embrapa/ CNPSo. 306p.

Fernandes FM, Mello Prado R \& Isepon OJ (2008) Residual effect of lime, nitrogen and zinc on dry matter production of Brachiaria decumbens in field conditions. Zootecnia Tropical, 26:125-131.

Grego CR \& Vieira SR (2005) Variabilidade espacial de propriedades físicas do solo em uma parcela experimental. Revista Brasileira de Ciência do Solo, 29:169-177.

GS+: Geostatistics for environmental sciences (2004) $7^{\mathrm{a}}$ ed. Plainwell, Gamma Desing Software. 159p.

Manarin CA (2000) Resposta fisiológica, bioquímicas e produtivas do Capim-Mombaça a doses de nitrogênio. Dissertação de Mestrado. Escola Superior de Agricultura "Luiz de Queiroz", Piracicaba. 58p.

Mendonça VZ, Mello LMM, Andreotti M, Pereira FCBL, Lima RC, Valério Filho WV \& Yano EH (2013) Avaliação dos atributos físicos do solo em consórcio de forrageiras e milho em sucessão com soja em região de cerrados. Revista Brasileira de Ciência do Solo, 37:251-259.

Milford R \& Minson DJ (1966). The feeding value of tropical pastures. $1^{\mathrm{a}}$ ed., Tropical pastures. London, Faber and Faber LTD. $106 \mathrm{p}$.

Montanari R (2009) Aspectos da produtividade do feijoeiro correlacionados com atributos do solo sob sistemas de manejo de elevado nível tecnológico. Tese de Doutorado. Universidade Estadual Paulista, Ilha Solteira. 172p.

Montanari R, Carvalho MP, Andreotti M, Dalchiavon FC, Lovera LH \& Honorato MAO (2010) Aspectos da produtividade do feijão correlacionados com atributos físicos do solo sob elevado nível tecnológico de manejo. Revista Brasileira de Ciência do Solo, 34:1811-1822.

Montanari R, Lima ES, Lovera LH, Godoy LTR, Henrique AF \& Dalchiavon FC (2013) Correlación de la productividad de un forraje con las propiedades físicas de un Ultisol en Aquidauana. Revista Ceres, 60:102-110.

Moreira JAA, Oliveira IP, Guimarães CM \& Stone LF (2005) Atributos químicos e físicos de um latossolo vermelho distrófico sob pastagens recuperada e degradada. Pesquisa Agropecuária Tropical, 35:155-161.

Pariz CM, Carvalho MP, Chioderoli CA, Casoti RA, Tosta FS, Nakayama FT \& Montanari R (2011) Correlação linear e espacial entre a produtividade de forragem de braquiária e os atributos físicos de um Latossolo Vermelho aluminoférrico. Revista Brasileira de Zootecnia, 32:221-227.

Pedreira JVS \& Mattos HB (1981) Crescimento estacional de vinte e cinco espécies ou variedades de capins. Boletim de Indústria Animal, 38:117-143.

Raij B van, Andrade JC, Cantarella H \& Quaggio JA (2001) Análise química para avaliação da fertilidade de solos tropicais. Campinas, Instituto Agronômico. 285p.

Queiroz Filho JL, Malheiros JR, Martinez MSG \& Oliveira Filho JJ (1986) Efeito da idade do corte e níveis de nitrogênio sobre o valor nutritivo da Brachiaria humidicula na região do brejo Paraibano. Agropecuária Técnica, 7:72-80.

Santos AR (1997) Diagnose nutricional e respostas do capimbraquiária sumetidos a doses de nitrogênio e enxofre. Tese de Doutorado. Escola Superior de Agricultura "Luiz de Queiroz", Piracicaba. $115 \mathrm{p}$. 
Santos MER, Fonseca DM \& Euclides VPB (2009) Produção de bovinos em pastagens de capim-braquiária diferidas. Revista Brasileira de Zootecnia, 38:635-642.

Schlotzhaver SD \& Littell RC (1997) SAS System for elementary statistical analysis. 2aed. Cary, NC. 905p.

Serrão EAD \& Simão Neto M (1971) Informações sobre duas espécies de gramíneas forrageiras do gênero Brachiaria na Amazônia: B. decumbens Stapf e B. ruziziensis Germain et Evrard. Belém, Instituto de Pesquisa e Experimentação Agropecuária do Norte. 31p.

Silva DJ \& Queiroz AC (2002) Análise de alimentos: métodos químicos e biológicos. $3^{\mathrm{a}} \mathrm{ed}$. Viçosa, Universidade Federal de Viçosa. 235p

Souza LS, Cogo NP \& Vieira SR (1998) Variabilidade de fósforo, potássio e matéria orgânica no solo, em relação a sistemas de manejo. Revista Brasileira de Ciência do Solo, 22:77-86.
Trangmar BB, Yost RS, Wade MK \& Uehara G (1985) Applications of geostatistics to spatial studies of soil properties. Advance Agronomy, 38:45-94.

Warrick AW \& Nielsen DR (1980) Spatial variability of soil physical properties in the field. In: Hillel D (Ed.) Applications of soil physics. New York, Academic Press. p.319-344.

Werner JC (1986) Adubação de pastagens. Nova Odessa, Instituto de Zootecnia. 49p. (Boletim Técnico, 18).

Werner JC, Paulino VT, Cantarella H \& Quaggio JA (1997) Forrageiras. In: Raij B Van, Cantarella H, Quaggio JÁ \& Furlani AMC (Eds.) Recomendações de calagem e adubação para o Estado de São Paulo. Campinas, Instituto Agronômico de Campinas. 285p. (Boletim técnico, 100). 